\title{
Oxidored-nitro domain-containing protein 1 promotes liver fibrosis by activating the Wnt/ $\beta$-catenin signaling pathway in vitro
}

\author{
TIANXIN XIANG $^{1 *}$, SHOUHUA ZHANG $^{2 *}$, NA CHENG $^{1}$, SHANFEI GE $^{1}$, \\ JIANGXIONG WEN $^{1}$, JUHUA XIAO ${ }^{3}$ and XIAOPING WU ${ }^{1}$ \\ ${ }^{1}$ Department of Infectious Disease, The First Affiliated Hospital of Nanchang University; \\ ${ }^{2}$ Department of General Surgery, Jiangxi Provincial Children's Hospital; ${ }^{3}$ Department of Ultrasound, \\ Jiangxi Provincial Maternal and Child Health Hospital, Nanchang, Jiangxi 330006, P.R. China
}

Received September 30, 2016; Accepted May 26, 2017

DOI: $10.3892 / \mathrm{mmr} .2017 .7165$

\begin{abstract}
Hepatic fibrosis is a characteristic of various types of chronic liver diseases, and may further develop into liver cirrhosis and liver cancer. Oxidored-nitro domain-containing protein 1 (NOR1) expression levels are greater in hepatitis, cirrhosis and hepatocellular carcinoma samples compared with from normal liver samples. However, the importance of NOR1 in liver fibrosis remains to be elucidated. The present study aimed to investigate the effect of NOR1 on the proliferation and matrix expression of human hepatic stellate cells (HSCs) in vitro. Additionally, the molecular mechanisms underlying the role of NOR1 in the activation of HSCs was investigated. The present study determined that transforming growth factor $\beta 1$ (TGF- $\beta 1$ ) may induce NOR1 expression in HSCs in a dose-dependent manner, as determined by reverse transcription-quantitative polymerase chain reaction and western blot analysis. NOR1-small hairpin (sh)RNA was transfected into TGF- $\beta 1$-treated HSCs to knock down NOR1. The MTT assay revealed that TGF- $\beta 1$-induced cell proliferation was significantly inhibited in the NOR1-shRNA group. In addition, NOR1 knockdown significantly inhibited TGF- $\beta 1$-induced protein expression of fibrosis indexes, including collagen 1,3 and $\alpha$-smooth muscle actin ( $\alpha$-SMA). Subsequently, NOR1-pcDNA3.1 was transfected into HSCs to overexpress NOR1. It was revealed that NOR1 overexpression may activate the Wnt/ $\beta$-catenin pathway in HSCs. The gain-of function experiments demonstrated that NOR 1 overexpression promoted cell proliferation and the expression of fibrosis indexes; however, these effects may be attenuated by dickkopf-1, an inhibitor of the $\mathrm{Wnt} / \beta$-catenin signaling pathway. In conclusion, the present
\end{abstract}

Correspondence to: Dr Xiaoping Wu, Department of Infectious Disease, The First Affiliated Hospital of Nanchang University, 17 Yongwaizheng Road, Nanchang, Jiangxi 330006, P.R. China E-mail:wu_xp1965@126.com

${ }^{*}$ Contributed equally

Key words: oxidored-nitro domain-containing protein 1, liver fibrosis, Wnt $/ \beta$-catenin signaling pathway, hepatic stellate cells study demonstrated that NOR1 activates HSCs and contributes to liver fibrosis in vitro and this effect was achieved through the activation of the Wnt/ $\beta$-catenin pathway. Therefore, the current study may provide a novel target for the treatment of chronic liver diseases.

\section{Introduction}

Liver fibrosis results from the imbalance between production and dissolution of the extracellular matrix, which is characteristic got the majority of chronic liver diseases (1). Advanced liver fibrosis leads to cirrhosis, liver failure and portal hypertension (2). The majority of patients with hepatocellular carcinoma (HCC) have a history of liver fibrosis and cirrhosis (3-6). The pathogenesis of liver remains to be fully elucidated and the recovery remains unsatisfactory. Therefore, the present study aimed to investigate the cellular and molecular mechanisms of the development of liver fibrosis, in order to improve the therapeutic options for the management of patients with chronic liver diseases.

Oxidored-nitro domain-containing protein 1 (NOR1) is a novel member of nitroreductases that was initially isolated from nasopharyngeal carcinoma (NPC) (7). The NOR1 gene shares $40 \%$ homology with nitroreductase from Escherichia coli and has the similar function of reducing nitrogen (7).

The NOR1 gene was associated with liver cancer (8-11). Transfection of the NOR1 gene in HepG2 cells leads to an increased expression of zinc finger protein, tumor necrosis factor receptor, and protein tyrosine phosphatase receptor (9), which are important proteins that are involved in gene transcription and signal transduction associated with cancer. Recently, Li et al (11) determined that there is a trend for increased positive rate of NOR1 expression from normal liver samples to hepatitis, cirrhosis and HCC samples, indicating that NOR1 may be a predictive biomarker in HCC development (11). To the best of our knowledge, the role of the NOR1 gene in liver fibrosis has not been previously reported.

The present study performed in vitro studies to investigate the effect of NOR1 on the proliferation and matrix expression of human hepatic stellate cells (HSCs). Additionally, the current study examined whether NOR1 exerts its effect on HSCs activation through the Wnt/ $\beta$-catenin signaling pathway. This may elucidate the role of NOR1 in liver fibrosis. 


\section{Materials and methods}

Cell culture and treatment. Human hepatic stellate cells (HSCs) were purchased from ScienCell Research Laboratories (Carlsbad, CA, USA) and cultured in Stellate Cell Medium (ScienCell Research Laboratories) supplemented with $10 \%$ fetal bovine serum (Gibco; Thermo Fisher Scientific, Inc., Waltham, MA, USA) in a humidified atmosphere at $37^{\circ} \mathrm{C}$ of $5 \% \mathrm{CO}_{2}$. Dickkopf-1 (DKK-1) and transforming growth factor $\beta 1$ (TGF- $\beta 1$ ) were obtained from Peprotech, Inc. (Rocky Hill, NJ, USA) and were dissolved in phosphate buffered saline (PBS). TGF- $\beta 1$ was diluted into concentrations of $1,2,5,10$ and $20 \mathrm{ng} / \mathrm{ml}$. HSCs were incubated with $200 \mathrm{ng} / \mathrm{ml}$ DKK-1 or different concentrations of TGF- $\beta 1$ at $37^{\circ} \mathrm{C}$ for indicated times.

Cell transfection. NOR1-small hairpin (sh)RNA and NOR1-pcDNA3.1 plasmid were synthesized by Shenzheng Zhonghong Boyuan Biological Technology Co., Ltd. (Shenzheng, China). They were transfected into HSCs using Lipofectamine 2000 (Invitrogen; Thermo Fisher Scientific, Inc.) according to the manufacturer's protocol. shRNAs were transfected at a final concentration of $50 \mathrm{nM}$; the plasmids were transfected at a final concentration of $1 \mu \mathrm{g}$.

Reverse transcription-quantitative polymerase chain reaction $(R T-q P C R)$. Total RNA was isolated from the cells using TRIzol (Thermo Fisher Scientific, Inc.) according to the manufacturer's protocol. cDNA was synthesized from $1 \mu \mathrm{g}$ of total RNA using Superscript III reverse transcriptase (Invitrogen; Thermo Fisher Scientific, Inc.). Primers used were: NOR1, 5'-tcaagggattcatccgagac-3' (forward) and 5'-ggatactcggatgtgcaggt-3' (reverse); and GAPDH, 5'-cgaccactttgtcaagctca-3' (forward) and 5'-aggggtctacatggcaactg-3' (reverse). A total of $1 \mu 1$ cDNA was used for qPCR using the SYBR-Green PCR kit (Thermo Fisher Scientific, Inc.) on a 7,900 real-time PCR system (Thermo Fisher Scientific, Inc.). PCR was performed with 40 cycles at $95^{\circ} \mathrm{C}$ for $30 \mathrm{sec}, 59^{\circ} \mathrm{C}$ for $30 \mathrm{sec}$ and $72^{\circ} \mathrm{C}$ for $30 \mathrm{sec}$. Gene expression was quantified using the $2^{-\Delta \Delta \mathrm{Cq}}$ method (12), normalizing $\mathrm{Cq}$ values to the internal control GAPDH. This experiment was replicated three times.

Western blot analysis. The cells were washed twice with PBS and lysed with cell lysis buffer (Biovison, Inc., Milpitas, CA, USA). Total protein concentration was determined using a BCA Protein Assay kit (Pierce, Thermo Fisher Scientific, Inc.). Total protein (20 $\mu \mathrm{g} / \mathrm{lane})$ were resolved by SDS-PAGE on a $10 \%$ gel and were then transferred onto nitrocellulose membranes (EMD Millipore, Billerica, MA, USA). After washing with PBS, the membranes were incubated at $4^{\circ} \mathrm{C}$ overnight with $5 \%$ non-fat milk, and then at $37^{\circ} \mathrm{C}$ for $2 \mathrm{~h}$ with the following primary antibodies: Rabbit polyclonal to NOR1 (cat. no. ab155535; dilution, 1:400), mouse monoclonal to wnt3a (cat. no. ab81614; dilution, 1:800), rabbit polyclonal to $\beta$-catenin (cat. no. ab16051; dilution, 1:500), rabbit polyclonal to Axin 2 (cat. no. ab32197; dilution, 1:400), mouse monoclonal to GAPDH (cat.no. ab8245; dilution, 1:1,000), mouse monoclonal to a-smooth muscle actin ( $\alpha$-SMA; cat. no. ab7817; dilution, 1:800; all from Abcam, Cambridge, MA, USA), rabbit polyclonal to collagen 1 (cat. no. BA0325; dilution, 1:500), mouse monoclonal to collagen 3 (cat. no. BM1625; dilution, 1:500; all from Boster Biological Technology, Ltd., Wuhan, China). After washing with TBST twice, the membranes were incubated with horseradish peroxidase-conjugated secondary antibodies [goat anti-rabbit IgG-HRP (cat. no. BA1054; dilution, 1:1,000) and goat anti-mouse IgG-HRP (cat. no. BA1050; dilution, 1:1,000); Boster Biological Technology, Ltd.] at $37^{\circ} \mathrm{C}$ for $1 \mathrm{~h}$. Immunoreactive bands were visualized with the enhanced chemiluminescence western blotting kit (Pierce; Thermo Fisher Scientific, Inc.).

MTT assay. The cells were seeded into the 96-well plates and maintained at $37^{\circ} \mathrm{C}$ in a humidified atmosphere of $\mathrm{CO}_{2}$ in air. After a $24 \mathrm{~h}$ incubation, the cells were treated with TGF- $\beta 1$ or DKK-1 for further incubation of 12, 24, 48 and $72 \mathrm{~h}$. At the end of cell incubation, $10 \mu \mathrm{l}$ MTT (Sigma-Aldrich; Merck Millipore, Darmstadt, Germany) was added into each well and incubated for $4 \mathrm{~h}$ at $37^{\circ} \mathrm{C}$. After that, $100 \mu \mathrm{l}$ dimethyl sulfoxide (Sigma-Aldrich; Merck Millipore) was added into each well for $30 \mathrm{~min}$. The absorbance at $490 \mathrm{~nm}$ was determined (Multiskan Ascent 354 microplate reader; Thermo Labsystems; Thermo Fisher Scientific, Inc.) for quantitative measurement of cell growth.

Statistical analysis. Data are expressed as the mean \pm standard deviation. Statistical analysis was performed with SPSS version 19.0 (IBM SPSS, Armonk, NY, USA) using Student's t-test or one-way analysis of variance followed by a least significant difference test. $\mathrm{P}<0.05$ was considered to indicate a statistically significant difference.

\section{Results}

Effect of TGF- $\beta 1$ on NOR1 expression in HSCs. The HSCs were treated with $1,2,5,10$ and $20 \mathrm{ng} / \mathrm{ml} \mathrm{TGF-} \beta 1$ for $48 \mathrm{~h}$ and then RT-qPCR and western blotting were performed to detect NOR1 expression. As presented in Fig. 1A, the mRNA expression level of NOR1 was increased with the increasing of TGF- $\beta 1$ concentration, the maximum effect was observed at $20 \mathrm{ng} / \mathrm{ml}$. NOR1 protein was absent in HSCs; however, an increase of NOR1 protein expression was observed in HSCs following treatment with 5, 10 and $20 \mathrm{ng} / \mathrm{ml} \mathrm{TGF-} \beta 1$ (Fig. 1B).

Effect of NORl on HSCs activation. NOR1-shRNA was transfected into HSCs to knock down NOR1 expression and the cells were treated with $20 \mathrm{ng} / \mathrm{ml}$ TGF- $\beta 1$ for $48 \mathrm{~h}$. Subsequently the cell proliferation and the expression of fibrosis indexes in HSCs was examined. As demonstrated in Fig. 2A, TGF- $\beta 1$-induced NOR1 protein expression was significantly suppressed following NOR1-shRNA transfection. The effect of NOR1 on HSCs proliferation was investigated using an MTT assay. HSCs proliferation increased under TGF- $\beta 1$ treatment; however, NOR1 knockdown significantly inhibited TGF- $\beta 1$-induced HSCs proliferation (Fig. 2B). The expression of fibrosis indexes in HSCs, such as collagen 1, 3 and $\alpha$-SMA was examined using western blot analysis. As presented in Fig. 2C, the protein expression levels of collagen 1, 3 and $\alpha$-SMA were significantly increased in HSCs group treated with TGF- $\beta 1$; however, NOR1-knockdown cells exhibited significantly reduced protein expression levels of collagen 1, 3 and $\alpha$-SMA. 
A

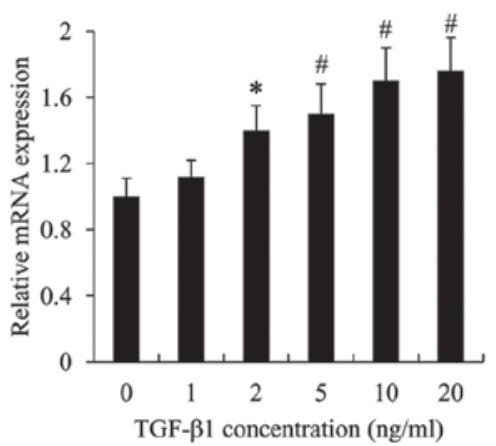

B

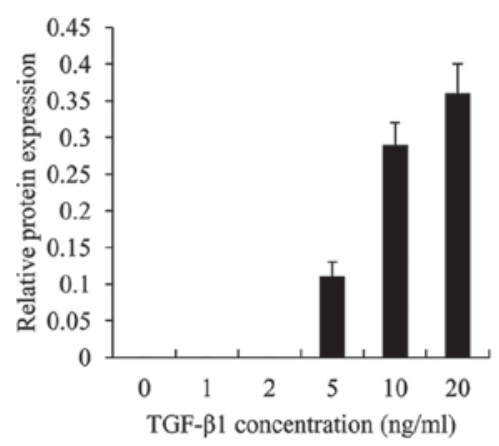

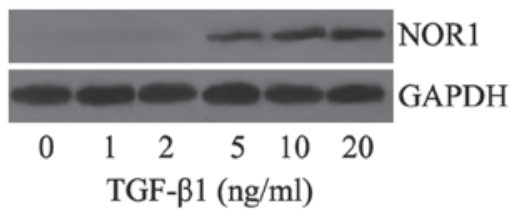

TGF- $\beta 1(\mathrm{ng} / \mathrm{ml})$

Figure 1. NOR1 expression was induced in HSCs by TGF- $\beta 1$ treatment. Relative NOR1 (A) mRNA and (B) protein expression levels in HSCs following treatment with $1,2,5,10$ and $20 \mathrm{ng} / \mathrm{ml} \mathrm{TGF-} \beta 1 .{ }^{*} \mathrm{P}<0.05$ and ${ }^{\#} \mathrm{P}<0.01 \mathrm{vs} .0 \mathrm{ng} / \mathrm{ml}$. NOR1, oxidored-nitro domain-containing protein 1 ; TGF- $\beta 1$, transforming growth factor $\beta 1$; HSCs, hepatic stellate cells.

A

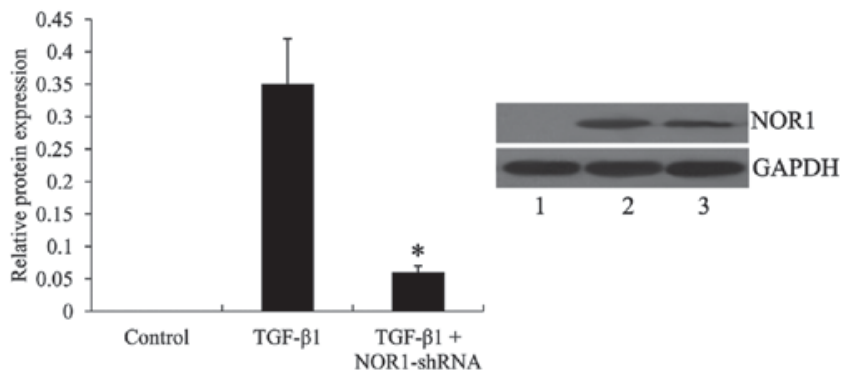

B

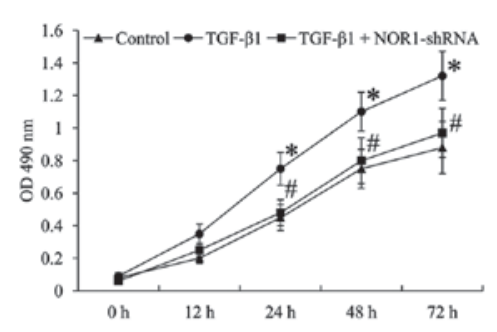

C

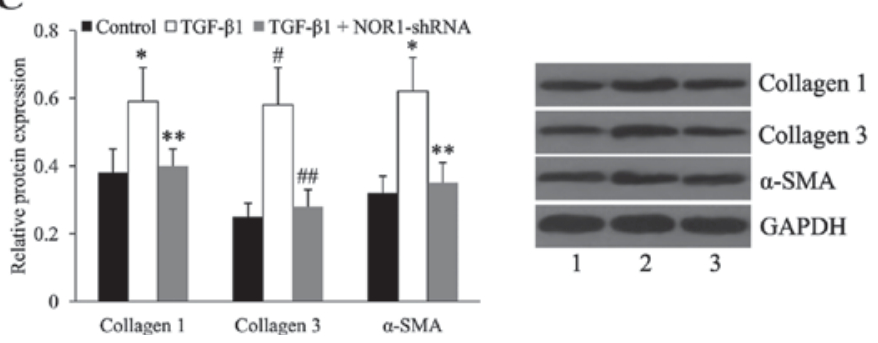

Figure 2. Effect of NOR1 on HSC activation. (A) Relative protein expression of NOR1 in TGF- $\beta 1$-treated HSCs following transfection with NOR1-shRNA. ${ }^{*} \mathrm{P}<0.01$ vs. TGF- $\beta 1$ group. (B) Cell proliferation of TGF- $\beta 1$-treated HSCs following transfection with NOR1-shRNA. " $\mathrm{P}<0.05$ vs. control group; ${ }^{*} \mathrm{P}<0.05$ vs. TGF- $\beta 1$ group. (C) Relative protein expression of collagen 1, collagen 3 and $\alpha$-SMA in TGF- $\beta 1$-treated HSCs following transfection with NOR1-shRNA. * $\mathrm{P}<0.05$ and ${ }^{\#} \mathrm{P}<0.01$ vs. control group; ${ }^{* *} \mathrm{P}<0.05$ and ${ }^{\# \#} \mathrm{P}<0.01$ vs. TGF- $\beta 1$ group. Lane 1 , control; lane 2 , TGF- $\beta 1$; lane 3 , TGF- $\beta 1+$ NOR1-shRNA. NOR1, oxidored-nitro domain-containing protein 1 ; TGF- $\beta 1$, transforming growth factor $\beta 1$; HSCs, hepatic stellate cells; $\alpha$-SMA, $\alpha$-smooth muscle actin; shRNA, small hairpin RNA.

Effect of NORI on Wnt/ß-catenin pathway in HSCs. NOR1-pcDNA3.1 was transfected into HSCs to overexpress NOR1 and the protein expression levels of wnt $3 \mathrm{a}, \beta$-catenin and Axin2 were quantified. NOR1 protein was highly expressed in HSCs transfected with NOR1-pcDNA3.1 (Fig. 3A). The protein expression levels of wnt $3 \mathrm{a}, \beta$-catenin and Axin 2 were significantly increased in NOR1-overexpressed cells compared with the control cells (Fig. 3B).

Wnt/ $\beta$-catenin pathway mediates the effect of NORI on HSCs activation. To investigate whether Wnt/ $\beta$-catenin pathway mediates the effect of NOR1 on HSCs activation, DKK1 was used to suppress Wnt/ $\beta$-catenin pathway and then cell proliferation and the expression of fibrosis indexes in HSCs were examined. As demonstrated in Fig. 4A, DKK1 treatment significantly inhibited the protein expression levels of wnt3a, $\beta$-catenin and Axin2 in HSCs. The MTT assay revealed that NOR1 overexpression promoted HSCs cell proliferation; however, this effect was reversed by DKK1 treatment (Fig. 4B). Additionally, the protein expression levels of collagen 1,3 and $\alpha$-SMA were significantly increased in HSCs transfected with NOR1-pcDNA3.1. DKK1 significantly inhibited the increased protein expression levels of collagen 1,3 and $\alpha$-SMA in HSCs (Fig. 4C).

\section{Discussion}

The NOR1 gene is expressed ubiquitously in human tissues (7). NOR1 is suggested to be a candidate tumor repressor gene in the development and progression of NPC (7), cervical (13) and prostate cancer (14). Previous studies reported the association between NOR1 and HCC (8-11). NOR1 is important in the chemical carcinogenesis of hepatic cancer (10). Overexpression 
A

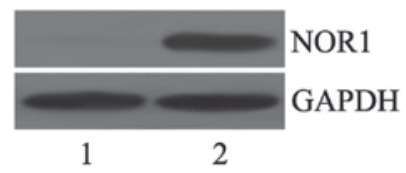

B

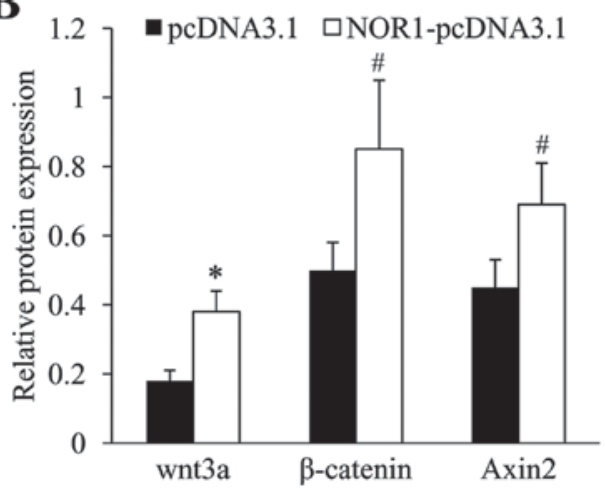

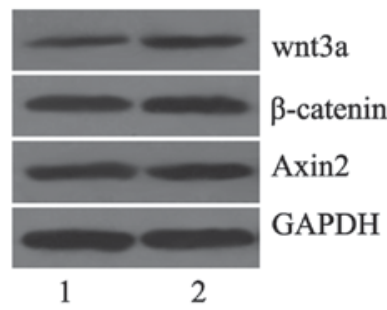

1
B

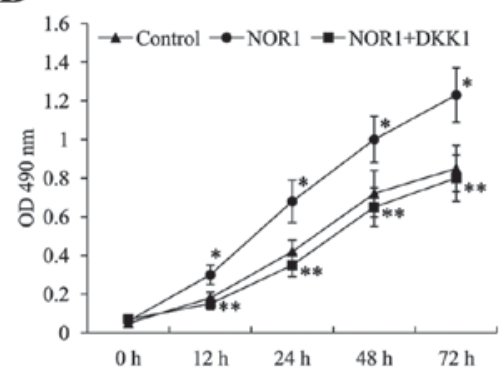

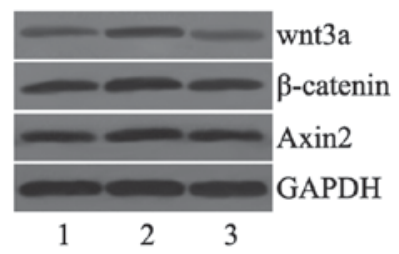

C

A

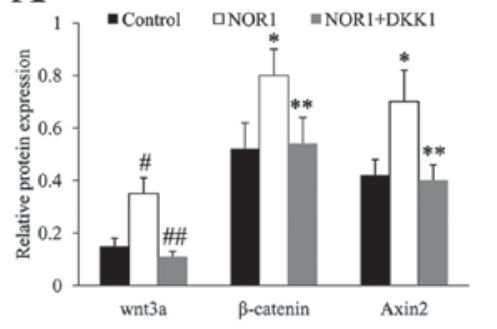

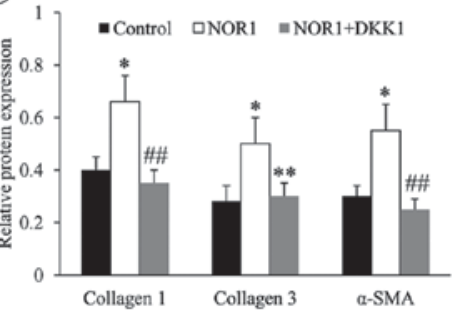

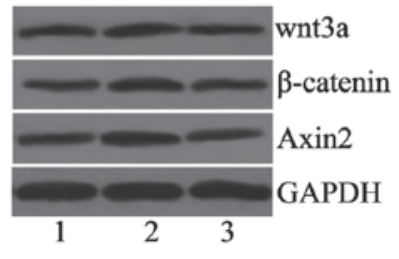

Figure 4. Wnt/ $\beta$-catenin signaling pathway mediates the effect of NOR1 on HSCs activation. (A) Relative protein expression of wnt3a, $\beta$-catenin and Axin2 in NOR1-overexpressed HSCs following DKK1 treatment. (B) DKK1 suppressed NOR1-induced HSCs proliferation. (C) DKK1 inhibited NOR1-induced collagen 1 , collagen 3 and $\alpha$-SMA expression. ${ }^{*} \mathrm{P}<0.05$ and ${ }^{\#} \mathrm{P}<0.01$ vs. control group; ${ }^{* *} \mathrm{P}<0.05$ and ${ }^{\# \#} \mathrm{P}<0.01$ vs. NOR1 group. Lane 1 , control; lane 2 , NOR1; lane 3, NOR1 + DKK1. NOR1, oxidored-nitro domain-containing protein 1; HSCs, hepatic stellate cells; $\alpha$-SMA, $\alpha$ smooth muscle actin; DKK1, dickkopf-1.

of NOR1 may enhance CB1954-induced cell death in HepG2 cells (10). Li et al (11) reported that NOR1 expression was increased in patients with $\mathrm{HCC}$ and its expression was correlated with clinicopathological parameters of HCC (11). It has been previously established that $90 \%$ of HCC cases are associated with fibrotic or cirrhotic livers $(5,6)$. Hepatic fibrosis may further develop into liver cirrhosis and liver cancer. The present study, revealed the role of NOR1 in liver fibrosis in vitro. Hepatic stellate cells are the major cell types involved in liver fibrosis $(15,16)$. When the liver is damaged, hepatic stellate cells are activated. The activated hepatic stellate cells are characterized by proliferation, contractility and collagen secretion, leading to cirrhosis (17-19). The present study performed in vitro experiments with HSCs to investigate the role of NOR1 in liver fibrosis. TGF- $\beta 1$ is an important profibrotic protein, which induces fibrosis in a variety of organs (20-23). The current study revealed that TGF- $\beta 1$ may induce NOR1 expression in HSCs in a dose-dependent manner. Furthermore, it was revealed that cell proliferation and the expression of fibrosis indexes induced by TGF- $\beta 1$ were significantly inhibited in NOR1-shRNA-transfected HSCs. These findings confirmed that NOR1 was involved in liver fibrosis and NOR1 knockdown attenuated TGF- $\beta 1$-induced HSCs activation.

Gui et al (10) reported that the expression of growth factor receptor-bound protein 2 and activated mitogen-activated protein kinase signal transduction were regulated by NOR1 in HepG2 cells (10). Shen et al (24) screened the genes differentially expressed in HepG2 cells transfected with NOR1 gene and the DNA microarray data revealed that 59 genes were upregulated and 103 genes were downregulated in NOR1-overexpressing HepG2 cells compared with the control (24). Subsequently, the present study investigated the molecular mechanisms underlying the role of NOR1 in liver fibrosis. Previous studies revealed that Wnt signaling has an essential role in the pathogenesis of liver fibrosis (25-27). Expression of Wnt genes was induced in activated HSC and Wnt signaling contributed to HSC activation and liver 
fibrogenesis (28). Blockage of the Wnt/ $\beta$-catenin signaling pathway inhibited HSC activation (29). In the present study, DKK-1 was used to block the Wnt signaling pathway to confirm whether it was involved in mediating NOR1-induced HSCs activation. The findings revealed that NOR1 overexpression may activate the Wnt/ $\beta$-catenin pathway in HSCs. The gain-of function experiments performed by the current study demonstrated that NOR1 activates HSCs and contributes to liver fibrosis; however, these effects may be attenuated by DKK1. These findings suggested that the Wnt/ $\beta$-catenin pathway mediates the effect of NOR1 on liver fibrosis.

In conclusion, the present study demonstrated that NOR1 promoted liver fibrosis in vitro and this effect was achieved through the activation of the $\mathrm{Wnt} / \beta$-catenin pathway. To the best of our knowledge, the present study was the first to reveal the role of NOR1 in liver fibrosis and suggested a novel target for the treatment of chronic liver diseases.

\section{Acknowledgements}

The current study was supported by The National Natural Science Foundation of China (grant no. 81460118), Science Technology Foundation of Jiangxi Province (grant no. 20141BBG70059), Health Development Planning Commission Science Foundation of Jiangxi Province (grant no. 2012A135), Education Department Scientific Research Foundation (grant no. GJJ14769) and The Foundation of Jiang xi Provincial Health Department (grant no. 2015047).

\section{References}

1. Friedman SL: Liver fibrosis-from bench to bedside. J Hepatol 38 (Suppl 1): S38-S53, 2003.

2. Koyama Y and Brenner DA: New therapies for hepatic fibrosis. Clin Res Hepatol Gastroenterol 39 (Suppl 1): S75-S79, 2015.

3. El-Serag HB and Rudolph KL: Hepatocellular carcinoma: Epidemiology and molecular carcinogenesis. Gastroenterology 132: 2557-2576, 2007.

4. Teo EK and Fock KM: Hepatocellular carcinoma: An Asian perspective. Dig Dis 19: 263-268, 2001.

5. Forner A, Llovet JM and Bruix J: Hepatocellular carcinoma. Lancet 379: 1245-1255, 2012

6. Bruix J and Sherman M; American Association for the Study of Liver Diseases: Management of hepatocellular carcinoma: An update. Hepatology 53: 1020-1022, 2011.

7. Nie X, Zhang B, Li X, Xiang J, Xiao B, Ma J, Zhou M, Zhu S, Lu H, Gui R, et al: Cloning, expression, and mutation analysis of NOR1, a novel human gene down-regulated in HNE1 nasopharyngeal carcinoma cell line. J Cancer Res Clin Oncol 129: 410-414, 2003

8. Gui R, Huang $\mathrm{R}$, Zhang JH, Wen $\mathrm{XH}$ and Nie XM MicroRNA-199a-5p inhibits VEGF-induced tumorigenesis through targeting oxidored-nitro domain-containing protein 1 in human HepG2 cells. Oncol Rep 35: 2216-2222, 2016.

9. Nie XM, Zhou JD, Huang ZY, Gui R, Li DQ and Tang H: Effects of a novel gene NOR(1) on the protein expression of HepG2 cell line. Xi Bao Yu Fen Zi Mian Yi Xue Za Zhi 24: 164-166, 2008 (In Chinese).

10. Gui R, Li D, Qi G, Suhad A and Nie X: Inhibition of Grb2-mediated activation of MAPK signal transduction suppresses NOR1/CB1954-induced cytotoxicity in the HepG2 cell line. Oncol Lett 4: 566-570, 2012.
11. Li DQ, Qiu M, Nie XM, Gui R and Huang MZ: Oxidored-nitro domain-containing protein 1 expression is associated with the progression of hepatocellular carcinoma. Oncol Lett 11: 3003-3008, 2016.

12. Livak KJ and Schmittgen TD: Analysis of relative gene expression data using real-time quantitative PCR and the 2(-Delta Delta $\mathrm{C}(\mathrm{T})$ ) method. Methods 25: 402-408, 2001.

13. Ouyang $\mathrm{J}, \mathrm{Wu}$ M, Huang $\mathrm{C}$, Cao L and Li G: Overexpression of oxidored-nitro domain containing protein 1 inhibits human nasopharyngeal carcinoma and cervical cancer cell proliferation and induces apoptosis: Involvement of mitochondrial apoptotic pathways. Oncol Rep 29: 79-86, 2013.

14. Shan Z, Hou Q, Zhang N, Guo L, Zhang X, Ma Y and Zhou Y: Overexpression of oxidored-nitro domain containing protein 1 induces growth inhibition and apoptosis in human prostate cancer PC3 cells. Oncol Rep 32: 1939-1946, 2014.

15. Lakner AM, Steuerwald NM, Walling TL, Ghosh S, Li T, McKillop IH, Russo MW, Bonkovsky HL and Schrum LW: Inhibitory effects of microRNA $19 \mathrm{~b}$ in hepatic stellate cell-mediated fibrogenesis. Hepatology 56: 300-310, 2012.

16. Oakley F, Meso M, Iredale JP, Green K, Marek CJ, Zhou X, May MJ, Millward-Sadler H, Wright MC and Mann DA: Inhibition of inhibitor of kappaB kinases stimulates hepatic stellate cell apoptosis and accelerated recovery from rat liver fibrosis. Gastroenterology 128: 108-120, 2005.

17. Gressner AM and Weiskirchen R: Modern pathogenetic concepts of liver fibrosis suggest stellate cells and TGF-beta as major players and therapeutic targets. J Cell Mol Med 10: 76-99, 2006.

18. Safadi R and Friedman SL: Hepatic fibrosis-role of hepatic stellate cell activation. MedGenMed 4: 27, 2002.

19. He Y,Huang C, Zhang SP, Sun X, Long XR and Li J: The potential of microRNAs in liver fibrosis. Cell Signal 24: 2268-2272, 2012.

20. Wermuth PJ, Li Z, Mendoza FA and Jimenez SA: Stimulation of transforming growth factor- $\beta 1$-induced Endothelial-To-Mesenchymal transition and tissue fibrosis by Endothelin-1 (ET-1): A novel profibrotic effect of ET-1. PLoS One 11: e0161988, 2016.

21. Meng XM, Nikolic-Paterson DJ and Lan HY: TGF- $\beta$ : The master regulator of fibrosis. Nat Rev Nephrol 12: 325-338, 2016.

22. Muñoz-Félix JM, González-Núñez M, Martínez-Salgado $C$ and López-Novoa JM: TGF- $\beta$ /BMP proteins as therapeutic targets in renal fibrosis. Where have we arrived after 25 years of trials and tribulations? Pharmacol Ther 156: 44-58, 2015.

23. Leask A and Abraham DJ: TGF-beta signaling and the fibrotic response. FASEB J 18: 816-827, 2004.

24. Shen CM, Nie XM and Li DQ: Screening of genes differentially expressed in HepG2 cells transfected with NOR1 gene using DNA microarray. Practical Prev Med 14: 609-611, 2007 (In Chinese).

25. Miao CG, Yang YY, He X, Huang C, Huang Y, Zhang L, Lv XW, Jin Y and Li J: Wnt signaling in liver fibrosis: Progress, challenges and potential directions. Biochimie 95: 2326-2335, 2013.

26. Guo Y, Xiao L, Sun L and Liu F: Wnt/beta-catenin signaling: A promising new target for fibrosis diseases. Physiol Res 61: 337-346, 2012.

27. Li W, Zhu C, Chen X, Li Y, Gao R and Wu Q: Pokeweed antiviral protein down-regulates $\mathrm{Wnt} / \beta$-catenin signalling to attenuate liver fibrogenesis in vitro and in vivo. Dig Liver Dis 43: 559-566, 2011.

28. Cheng JH, She H, Han YP, Wang J, Xiong S, Asahina K and Tsukamoto H: Wnt antagonism inhibits hepatic stellate cell activation and liver fibrosis. Am J Physiol Gastrointest Liver Physiol 294: G39-G49, 2008.

29. Ge WS, Wang YJ, Wu JX, Fan JG, Chen YW and Zhu L: $\beta$-catenin is overexpressed in hepatic fibrosis and blockage of Wnt/ $\beta$-catenin signaling inhibits hepatic stellate cell activation. Mol Med Rep 9: 2145-2151, 2014. 